\title{
Projected number of children with isolated spina bifida or Down syndrome in England and Wales by 2020
}

Kate E Best ${ }^{\mathrm{a}}$, PhD, Svetlana V Glinianaia ${ }^{\mathrm{a}}, \mathrm{MD}$, Raghu Lingam ${ }^{\mathrm{a}}, \mathrm{MBChB}, \mathrm{MRCPCH}, \mathrm{PhD}$, Joan K Morris ${ }^{\mathrm{b}}$, PhD, Judith Rankin ${ }^{\mathrm{a}}$, PhD.

a Institute of Health \& Society, Newcastle University, Newcastle upon Tyne, UK

b Wolfson Institute of Preventive Medicine, Barts and The London School of Medicine and Dentistry, Queen Mary University of London, London, UK.

Address Correspondence to: Prof. Judith Rankin, Institute of Health \& Society, BaddileyClark Building, Newcastle University, Newcastle upon Tyne, NE2 4AX, England, UK. judith.rankin@ncl.ac.uk, +44 (0)1912085267

Short title: Children with spina bifida and Down syndrome by 2020

Funding source: This work was funded by the Newlife Foundation for Disabled Children (SG/15-16/02) and SVG was funded by Public Health England.

Financial Disclosure: The authors have no financial relationships relevant to this article to disclose.

Conflict of interest statement: The authors have no conflicts of interest relevant to this article to disclose.

Abbreviations: NorCAS $=$ Northern Congenital Abnormality Survey, NDSCR $=$ National Down Syndrome Cytogenetic Register, $\mathrm{CI}=$ confidence interval, $\mathrm{iRR}=$ incidence rate ratio, $\mathrm{HR}=$ Hazard ratio

\section{Contributors Statement:}

KEB designed the analysis plan, performed the analysis, drafted the initial manuscript and approved the final manuscript. SVG co-designed the study, participated in the acquisition, preparing and cleaning of the data, critically appraised the manuscript and approved the final version of the paper. RL co-designed the study, critically appraised the manuscript and approved the final version of the paper. JM provided the NDSCR data, provided advice on the statistical analysis (particularly regarding the comparison to her previous paper), critically appraised the manuscript and approved the final version of the paper. JR conceived the project, co-designed the study, critically appraised the manuscript and approved the final version of the paper. 


\begin{abstract}
Children with major congenital anomalies often require lifelong access to health and social care services. Estimating future numbers of affected individuals can aid health and social care planning. This study aimed to estimate the number of children aged 0-15 years living with spina bifida or Down syndrome in England and Wales by 2020. Cases of spina bifida and Down syndrome born during 1998-2013 were identified from the Northern Congenital Abnormality Survey and the National Down Syndrome Cytogenetic Register, respectively. The number of infants born with spina bifida during 1998-2019 were estimated by applying the average prevalence rate in the North of England to actual and projected births in England and Wales. Poisson regression was performed to estimate the number of infants born with Down syndrome in England and Wales during 1998-2013 and 2004-2019. The numbers of children aged 0-15 living with spina bifida or Down syndrome in 2014 and in 2020 were then estimated by multiplying year- and age-specific survival estimates by the number of affected births. An estimated 956 children with isolated spina bifida, 623 children with spina bifida and hydrocephalus and 11,592 children with Down syndrome aged 0-15 years will be living in England and Wales by 2020, increases of 7.2\%, $12.0 \%$ and $12.7 \%$ since 2014, respectively. Due to improvements in survival, an increase in population size and changes in maternal age distribution at delivery, we anticipate further increases in the number of children living with spina bifida or Down syndrome by 2020.
\end{abstract}




\section{Introduction}

Spina bifida occurs in 4 per 10,000 pregnancies in Europe, with approximately $31 \%$ of these resulting in live births.(1) Infant survival for children born with spina bifida has been reported as $71 \%$ in the UK (1985-2003) and $87 \%$ in the US (1979-1994).(2, 3) Down syndrome (trisomy 21) affects approximately 22 per 10,000 pregnancies in Europe, with the risk increasing with maternal age.(1,4) Fifty percent of cases result in a termination of pregnancy or fetal death and, of the live births, infant survival is around $90 \% . .(1,5)$ The live birth prevalence of Down syndrome has increased because of the increased proportion of women entering pregnancy at advanced maternal age.(6) However, terminations of Down's syndrome pregnancies due to an increase and improvements in antenatal screening have caused the number of live births with Down's syndrome to remain constant $(6,7)$ Survival of affected individuals also improved over time.(3, 8, 9). While several studies worldwide have reported the live birth prevalence and survival of Down syndrome and spina bifida, $(8,10-14)$ to our knowledge none have combined these estimates to predict the population size of children with these conditions.

Spina bifida and Down syndrome are examples of severe structural and chromosomal congenital anomalies respectively, where the affected individuals require lifelong specialised health care. This can include: complex surgeries, out-patient follow-up and access to disability equipment and special education, all of which come at substantial financial and emotional cost to society and the family.(15-17) For example, a US study reported a 13-fold increase in private care expenditures for children with spina bifida compared to the general population.(18) Therefore, it is important to estimate the number of individuals living with these conditions in order to make some inferences on future costs. Given that the transition from pediatric to adult care occurs around age 16 in the UK, and children can require 
additional support in adaptation to changes in the service provision, it is important to estimate the number of children of this age living with these conditions.

We estimated the number of children aged 0-15 years who will be living with spina bifida or Down syndrome in England and Wales by the beginning of 2020. 


\section{Patients and Methods}

\section{Data sources}

The Northern Congenital Abnormality Survey (NorCAS) was a population-based register that collected data on cases of congenital anomalies delivered to women residing in the North of England, covering approximately 29,000 births per year. Cases of congenital anomaly diagnosed before age 12 years (16 prior to 2002) were included on the NorCAS. The survey used multiple sources of case ascertainment, such as antenatal ultrasonography, fetal medicine departments, cytogenetic laboratories, the regional cardiology centre, pathology departments, and paediatric surgery. The register was active between 1985-2014, but was superseded by the National Congenital Anomaly and Rare Disease Registration Service (NCARDRS) in March 2015. In 2008, there was a one-off data linkage between the Office for National Statistics (ONS) for England death registrations and data for NorCAS cases born between 1985-2003. More information regarding the NorCAS and data linkage is available elsewhere.(2)

The National Down Syndrome Cytogenetic Register (NDSCR) was a population-based register that collected data on cases of Down syndrome born to mothers resident in England and Wales. The register worked in collaboration with the Association of Clinical Cytogeneticists and their members, meaning that when a case of Down syndrome was diagnosed, either prenatally or postnatally, a form was completed by the corresponding regional cytogenetic laboratory and notified to the NDSCR. More information on the NDSCR can be found elsewhere.(19) For each case, data on year of birth, maternal age and place of residence (Wales, England: North East, North West, Yorkshire and the Humber, East, East Midlands, West Midlands, South East, South West, and London) was recorded (among other variables). 
Live births between $1^{\text {st }}$ January 1998 and $31^{\text {st }}$ December 2016 by year, region and maternal age category were available from the ONS for England and Wales. Projected births between 1st January 2017 and 31st December 2019, by region, year of birth and maternal age were available from the ONS for England (20) and by year of birth and maternal age for Wales.(21)

\section{Case classification and inclusion}

The NorCAS recorded text descriptions and WHO ICD-10 codes for up to six individual congenital anomalies per case (22). These were categorised into group (the organ system affected, e.g. 'nervous system'), subtype (the specific condition, e.g. 'spina bifida'), and syndrome (e.g. 'Di George syndrome') based on EUROCAT guidelines (23, 24). Cases with more than one ICD code were assigned a primary diagnosis using an hierarchical approach described previously with the highest allocated from: 1) chromosomal syndromes; 2) genetic syndromes; 3 ) skeletal dysplasias; 4) other genetic anomalies (resulting from microdeletions or mutations); or 5) other syndromes of non-genetic origin $(2,23)$. Isolated cases were allocated to their primary anomaly group and subtype. Cases with two or more structural anomalies were reviewed to identify a primary group or subtype, or to assign a diagnosis of multiple anomalies (two or more unrelated structural anomalies across separate organs). Live born cases of spina bifida (ICD-10: Q05) delivered between $1^{\text {st }}$ January 1998 and $31^{\text {st }}$ December 2013 in the North of England were identified from the NorCAS. Cases of spina bifida with chromosomal or additional structural anomalies were excluded because survival and temporal trends are different in these cases. However, cases with spina bifida and hydrocephalus were included but coded separately, because hydrocephalus occurs as a direct result of spina bifida and is part of the same condition.(25) 
Data on live born cases of Down syndrome (ICD-10 Q90) delivered between $1^{\text {st }}$ January $1998-31^{\text {st }}$ December 2013 in England and Wales by year, maternal age $(<30,30-34$ and $\geq 35$ years) and region were obtained from the NDSCR. Cases of Down syndrome were only included if there was cytogenetic evidence that would lead to a diagnoses of Down syndrome. Cases of Down syndrome with multiple congenital anomalies were included as the additional anomalies are likely to be part of the Down syndrome.

\section{Statistical Analysis}

Using Poisson regression models with year of birth as the explanatory variable, we found no evidence of a trend over time in isolated spina bifida $(\mathrm{p}=0.17)$ or in spina bifida with hydrocephalus $(\mathrm{p}=0.54)$ born in the North of England between 1998-2013. Therefore, the number of cases of spina bifida born in England and Wales between 1998-2019 was estimated by multiplying the average spina bifida North of England live birth rate during 1998-2013 by the number of actual (1998-2016) and predicted (2017-2019) live births in England and Wales between 2014-2019.

Using a multivariable Poisson regression model, we found that year of birth, maternal age, region, and interactions between year of birth and maternal age, and year of birth and region, were all significantly associated with the live birth prevalence of Down syndrome (all $\mathrm{p}<0.001)$. Therefore, using the actual and predicted number of live births in England and Wales, the number of live births affected by Down syndrome between 2014-2019 were estimated from the Poisson model. In a sensitivity analysis we estimated the number of live births using the average Down syndrome live birth prevalence rate between 1998-2013 applied to the number of live births between 2014-2019. Maternal age data was missing in $11.5 \%$ of Down syndrome cases. Therefore, the proportion of cases within each maternal age category was multiplied by the total number of cases to provide estimated case numbers. 
Spina bifida and Down syndrome survival according to birth year (1985-2003) was modelled using Royston-Parmar regression, a type of survival model that uses a flexible parametric approach (with cubic splines) to model baseline hazard(26), adjusted for year of birth. The model was extrapolated to estimate survival for children born up to 2020 at various ages e.g. for children born in 2004, 16 year survival (i.e. the age reached by 2020) was estimated specific to this year. Survival was assumed to be equal in all regions of England. These survival estimates were multiplied by the actual and predicted case numbers born each year and summed to estimate the number of children with spina bifida or Down syndrome aged 015 years by 2014 and 2020 . 


\section{Results}

\section{Live birth prevalence}

There were 78 live born cases of spina bifida notified to the NorCAS between 1998-2013, including $33(42.3 \%)$ with hydrocephalus. In the same time period, there were 509,679 live births in the North of England, giving a live birth prevalence of 0.9 (95\% CI: 0.6-1.2) per 10,000 live births for isolated spina bifida and 0.6 (95\% CI: 0.4-0.9) for spina bifida with hydrocephalus.

There were 10,985 live born cases of Down syndrome notified to the NDSCR between 19982013. In the same period, there were 1,060,5934 live births in England and Wales. The overall live birth prevalence of Down syndrome between 1998-2013 in England and Wales was 10.4 [95\% CI: 10.2-10.6] per 10,000 live births, with prevalence rates of 5.2 [95\% CI: 5.0-5.4], 8.3 [95\% CI: 8.0-8.6] and 27.7 [95\% CI: 27.0-28.4] per 10,000 live births in mothers aged $<30,30-34$ and $\geq 35$ years.

The number of actual (1998-2016) and projected live births (2017-2019) in England and Wales by maternal age are shown in Figure 1 . The actual and predicted number of babies born with spina bifida or Down syndrome are shown in Figure 2.

\section{Survival}

There were 195 live born cases of spina bifida notified to the NorCAS between 1985-2003, including 90 (46.2\%) with hydrocephalus. Twenty year survival was 50.0\% [95\% CI: 39.759.5\%] for spina bifida with hydrocephalus and 86.7\% [95\% CI: 77.7-92.2\%] for isolated spina bifida (Figure 3A). The risk of mortality decreased by $7 \%$ per year in cases with and without hydrocephalus, although the trends were not statistically significant (hazard ratio 
$(\mathrm{HR})=0.93,95 \%$ CI: $0.87-1.00 ; \mathrm{p}=0.06$ and $\mathrm{HR}=0.93,95 \%$ CI: $0.81-1.06 ; \mathrm{p}=0.27$, respectively).

There were 697 live born cases of Down syndrome notified to the NorCAS between 1985 2003. Twenty year survival was $82.9 \%$ [95\% CI: 79.7-85.7] (Figure 3B), with the risk of mortality decreasing significantly by $7 \%$ per year $(H R=0.93,95 \%$ CI $0.89-0.96 ; p<0.001)$. There was no significant association between (continuous) maternal age at delivery and mortality $(\mathrm{HR}=0.99,95 \%$ CI: $0.97-1.02 ; \mathrm{p}=0.617)$. Survival estimates conditioned on year of delivery are shown in Tables 1 and 2 .

\section{Survivors}

An estimated 956 and 623 children aged 0-15 years are expected to be living with isolated spina bifida or spina bifida with hydrocephalus by the beginning of 2020 (Table 2), of whom approximately 307 and 209 will be aged 0-4, 366 and 242 will be aged 5-10, 283 and 173 will be aged 11-15, respectively. An estimated 11,592 children aged 0-15 years are expected to be living with Down syndrome in 2020 (Table 2), of whom 3875 will be aged 0-4, 4321 will be aged 5-10 and 3396 will be aged 11-15 years old. The estimated case numbers are greater in 2020 than in 2014, when 892 children were living with isolated spina bifida, 556 with spina bifida and hydrocephalus and 10,285 with Down syndrome (Table I1), estimated increases of $7.2 \%(\mathrm{n}=64), 12.0 \%(\mathrm{n}=67)$ and $12.7 \%(\mathrm{n}=1,307)$, respectively.

\section{Sensitivity analysis}

Had we assumed the rate of Down syndrome cases born between 2014-2019 was equal to the average rate in England and Wales between 1998-2013, there would have been 12,100 births with Down syndrome during 2004-2019, of whom 11,593 may have survived until 2020. Compared to using the modelling methods, this was an excess of just one case. 


\section{Discussion}

To our knowledge, this is the only study to predict future numbers of spina bifida and Down syndrome in England \& Wales. We predict that compared to 2014, there will be a $12.7 \%$, $7.2 \%$ and a $12.0 \%$ increase in the population of children aged $0-15$ years living with Down syndrome, isolated spina bifida and spina bifida with hydrocephalus in England and Wales by 2020, respectively.

We used data from high quality population-based registers that are notified of cases from multiple sources, ensuring high case ascertainment. Survival estimates were derived from NorCAS data linked to ONS death registrations, where $98 \%$ of cases were traced.(2) We used conditional survival estimates to account for temporal changes in survival and we used agespecific survival for more accurate estimates of the number of individuals living with the conditions. We examined spina bifida according to the co-occurrence of hydrocephalus, which is important given the difference in disease severity and therefore the different services and disability aids required by affected individuals. We also compared estimated case numbers of Down syndrome using two different methods, finding a discrepancy of only one case.

We estimated survival between 2003-2019 assuming the trend in survival stayed on the same trajectory as between 1985-2003. Therefore, our survival estimates do not account for any changes in services or events that may have set the trend in survival on a different trajectory. Similarly, we assumed that the live birth prevalence of spina bifida between 2014-2019 would be the same as the average prevalence between 2000-2013. Our trends therefore do not account for any improvements in prenatal diagnosis rates or changes in the prevalence of spina bifida risk factors, such as maternal obesity(27) A similar assumption was made for the estimation of the live birth prevalence of Down syndrome between 2014-2019. Therefore, the 
numbers we have projected do not account for the introduction of non-invasive prenatal diagnosis (NIPD), which may increase the number of women opting for screening and therefore the rate of terminations for fetal anomaly and decrease the number of live births. However, NIPD is currently only available in the private setting, with an evaluative roll out in the NHS planned for late 2018 or 2019(28), so we would not expect this to have greatly impacted our estimations. Our estimates may be a useful comparison when evaluating the impact of NIPD in the UK in the future. Our estimated case numbers took into account changes in the birth population, using ONS population projections which are based on a variety of variables including fertility, mortality and migration. While our estimates of survival for spina bifida without hydrocephalus are comparable to a previous study in a similar era (1979-1994), our estimates for spina bifida with hydrocephalus are lower.(3) This is perhaps related to different case mixes due to differences in termination rates or uptake of folic acid between the populations.

We assumed that the prevalence of spina bifida was the same in England and Wales as it was in the North of England. However, the North of England has greater smoking rates than other regions of England and Wales.(29) A recent systematic review showed that smoking during pregnancy increases the odds of spina bifida by 55\%, meaning the North of England may have a slightly increased prevalence of spina bifida.(30) Compared to the rest of England and Wales, the North of England has a lower proportion of residents from ethnic minority groups.(31) This may have resulted in an increase in the prevalence of spina bifida in the North of England given that several US studies have reported a decreased risk of spina bifida in non-Hispanic Blacks compared to Whites. $(32,33)$ Similarly, a systematic review showed that compared to Caucasian women, South Asian and African women in the UK had lower preconception use of folic acid, which reduces the risk of neural tube defects.(34) The North 
of England also has high levels of socioeconomic deprivation and a lower proportion of older mothers, which may have conversely inflated the prevalence of spina bifida. $(35,36)$

We were only able to model maternal age categorically, which does not entirely capture the association with maternal age. For example, the categorisation of maternal age $\geq 35$ does not account for the rising maternal age within this group, i.e. over time the fertility rate has been rising in mothers aged 40 and above.(36) This may explain why we identified an increasing trend in Down syndrome prevalence in mothers aged $\geq 35$. Additionally, $11 \%$ of the Down syndrome cases had missing maternal age data. We assumed that this data was missing at random and therefore inflated the number of cases within each maternal age category. If the data was not missing at random (i.e. if the missingness occurred more for one maternal age category than for another), then this approach may mean our trends over time are slightly inaccurate. Given only $11 \%$ of cases had missing maternal age however, this is not likely to have had a great impact on the projections.

A previous study estimated the number of individuals living with Down syndrome in England and Wales by 2011 was 37,090, with 10,438 of these being aged $\leq 18$.(37) For 2014, we estimated that there would have been 10,285 children aged 0-15 years, which suggests we estimated a higher number of individuals than the previous study. This was likely due to our different estimates of first year survival, which were greater in our study than in Wu et al's, which estimated survival by pooling rates from previous publications.

We estimate that the population of children aged 0-15 with spina bifida or Down syndrome will increase slightly from 2014. This increase is mainly due to the increasing number of births in the population with the increase in cases of Down syndrome being associated with the increasing number of births to mothers aged over 35. A likely increase of older mothers in the $\geq 35$ group may have contributed to a further increase in the prevalence of Down 
syndrome. The small yearly increases in survival also contributed to the increase in the number of children living with spina bifida and Down syndrome between 2014-2020. This increase is likely going to be observed in other populations, including the United States. Therefore, this estimation of future cases is important for planning specialised health and care services, including the associated costs. This is important given that children with spina bifida or Down syndrome have a 13-fold increase in private care expenditures compared to the general population of the US. $(18,38)$ Therefore, it is important to estimate the number of individuals living with these conditions in order to make some inferences on future costs. This is of particular importance given the changes in funding currently proposed in the UK and US health sectors.

\section{Conclusions}

Children with spina bifida and Down syndrome often have lifelong specialised health and social care needs. Our estimated increase in the numbers of affected individuals can aid healthcare planning and cost estimation to ensure these services are in place, which is particularly important given current austerity in the UK.

\section{Ethical approval}

The NorCAS has approval from the Confidentiality Advisory Group of the Health Research Authority (PIAG 2-08(e)/2012), to hold data without consent and as part of the British Isles Network of Congenital Anomaly Registers (BINOCAR), ethics committee approval (09/H0405/48) to undertake studies involving their data. Since 2003, the NDSCR as a part of BINOCAR has been given permission to operate without informed consent (2-08(e)/2002). In 2009 the application of the NDSCR for ethics approval from the Trent multi-centre research ethics committee (MREC), as part of BINOCAR, was also approved (09/H0405/48).

\section{Acknowledgements}

We thank the staff at the NorCAS and the NDSCR and the link clinicians for their continued support. We thank Prof Steve Rushton for statistical advice. NorCAS was funded by the Healthcare Quality Improvement Partnership until April 2013 and Public Health England thereafter.

\section{Figure legends}

Figure 1 Actual and predicted population live births in England and Wales by maternal age 
Figure 2 Actual and predicted number of births affected by A) spina bifida or B) Down syndrome in England \& Wales

Figure 3 Kaplan-Meier survival estimates for cases born 1985-2003 in the North of England 


\section{References}

1. EUROCAT. EUROCAT prevalence tables 2000-2014. 2016.

http://www.eurocat-network.eu/accessprevalencedata/prevalencetables

2. Tennant PWG, Pearce MS, Bythell M, Rankin J. 20-year survival of children born with congenital anomalies: a population-based study. The Lancet. 2010;375:64956.

3. Wong LY, Paulozzi LJ. Survival of infants with spina bifida: a population study, 1979-94. Paediatric and perinatal epidemiology. 2001;15:374-8.

4. Loane M, Morris JK, Addor M-C, et al. Twenty-year trends in the prevalence of Down syndrome and other trisomies in Europe: impact of maternal age and prenatal screening. European Journal of Human Genetics. 2013;21:27-33.

5. Irving C, Basu A, Richmond S, Burn J, Wren C. Twenty-year trends in prevalence and survival of Down syndrome. European Journal of Human Genetics. 2008;16:1336-40.

6. Morris JK, Alberman E. Trends in Down's syndrome live births and antenatal diagnoses in England and Wales from 1989 to 2008: analysis of data from the National Down Syndrome Cytogenetic Register. BMJ. 2009;339:b3794.

7. Khoshnood B, Loane M, De Walle H, et al. Long term trends in prevalence of neural tube defects in Europe: population based study. BMJ. 2015;351:h5949.

8. Rankin J, Tennant PW, Bythell M, Pearce MS. Predictors of survival in children born with Down syndrome: a registry-based study. Pediatrics.

2012;129:e1373-81.

9. Shin M, Kucik JE, Siffel C, et al. Improved Survival Among Children with Spina Bifida in the United States. The Journal of Pediatrics. 2012;161:1132-7.e3. 10. Morris JK, Mutton DE, Alberman E. Revised estimates of the maternal age specific live birth prevalence of Down's syndrome. Journal of Medical Screening. 2002;9:2-6.

11. Savva GM, Walker K, Morris JK. The maternal age-specific live birth prevalence of trisomies 13 and 18 compared to trisomy 21 (Down syndrome). Prenatal Diagnosis. 2010;30:57.

12. Zaganjor I, Sekkarie A, Tsang BL, et al. Describing the Prevalence of Neural Tube Defects Worldwide: A Systematic Literature Review. PLoS ONE. 2016;11:e0151586.

13. Weijerman ME, van Furth AM, Vonk Noordegraaf A, van Wouwe JP, Broers CJM, Gemke RJBJ. Prevalence, Neonatal Characteristics, and First-Year Mortality of Down Syndrome: A National Study. The Journal of Pediatrics. 2008;152:15-9.

14. Oakeshott P, Hunt GM, Poulton A, Reid F. Expectation of life and unexpected death in open spina bifida: a 40-year complete, non-selective, longitudinal cohort study. Developmental Medicine \& Child Neurology. 2010;52:749-53.

15. Dunlap B, Shelke K, Salem SA, Keith LG. Folic acid and human reproduction - ten important issues for clinicians. Journal of Experimental \& Clinical Assisted Reproduction. 2011;8:2.

16. Radcliff E, Cassell CH, Tanner JP, et al. Hospital use, associated costs, and payer status for infants born with spina bifida. Birth Defects Research Part A:

Clininical and Molecular Teratology. 2012;94:1044-53. 
17. Geelhoed EA, Bebbington A, Bower C, Deshpande A, Leonard H. Direct health care costs of children and adolescents with Down syndrome. The Journal of Pediatrics. 2011;159:10.1016/j.jpeds.2011.06.007.

18. Ouyang L, Grosse SD, Armour BS, Waitzman NJ. Health care expenditures of children and adults with spina bifida in a privately insured US population. Birth defects research Part A: Clinical and molecular teratology. 2007;79:552-8.

19. Morris JK, Springett A. The National Down syndrome cytogenic register for England and Wales: 2013 annual report. 2014.

http://www.wolfson.qmul.ac.uk/images/files/pdf/annrep2013 FINAL.pdf

20. Office for National Statistics (ONS). Subnational Population Projections, Births by age of mother: SNPP Z3. 2014.

wWw.ons.gov.uk/peoplepopulationandcommunity/populationandmigration/population projections/datasets/birthsbyageofmotherz3

21. Office for National Statistics (ONS). Population projections for Wales. 2014.

22. World Health Organization. Congenital malformations, deformations and chromosomal abnormalities (Q00-Q99). . International statistical classification of diseases and related health problems: 10th revision. 2010.

23. European Surveillance of Congenital Anomalies. EUROCAT syndrome guide: definition and coding of syndromes. 2008. www.eurocat-

network.eu/content/EUROCAT-Syndrome-Guide-6-2008.pdf. Accessed 12 February 2014.

24. European Surveillance of Congenital Anomalies. Chapter 3.3: EUROCAT Subgroups of Congenital Anomalies (Version 2014). 2014. http://www.eurocatnetwork.eu/aboutus/datacollection/guidelinesforregistration/guide1_4

25. Yeates KO, Fletcher JM, Dennis M. 9 Spina bifida and hydrocephalus. Textbook of Clinical Neuropsychology. 2016:128.

26. Royston P, Parmar MKB. Flexible parametric proportional-hazards and proportional-odds models for censored survival data, with application to prognostic modelling and estimation of treatment effects. Statistics in Medicine. 2002;21:217597.

27. Stothard KJ, Tennant PWG, Bell R, Rankin J. Maternal overweight and obesity and the risk of congenital anomalies: a systematic review and meta-analysis. Jama. 2009;301:636-50.

28. Public Health England. NHS public health functions agreement 2017-18 Service specification no.16 NHS Fetal Anomaly Screening Programme -Screening for Down's, Edwards' and Patau's Syndromes (Trisomy 21, 18 \& 13). In: NHS England, ed.2017. https://www.england.nhs.uk/wp-content/uploads/2017/05/serv-spec-16.pdf 29. Office for National Statistics (ONS). Cigarette smoking by region, by country. 2014.

WwW.ons.gov.uk/peoplepopulationandcommunity/housing/datasets/referencetable09ci garettesmokingbyregionbycountry

30. Wang M, Wang Z-P, Gong R, Zhao Z-T. Maternal smoking during pregnancy and neural tube defects in offspring: a meta-analysis. Child's Nervous System. 2014;30:83-9.

31. Office for National Statistics (ONS). Population of the United Kingdom by Country of birth and nationality. 2016. 
www.ons.gov.uk/peoplepopulationandcommunity/populationandmigration/internation almigration/datasets/populationoftheunitedkingdombycountryofbirthandnationality 32. Williams LJ, Rasmussen SA, Flores A, Kirby RS, Edmonds LD. Decline in the Prevalence of Spina Bifida and Anencephaly by Race/Ethnicity: 1995-2002.

Pediatrics. 2005;116:580-6.

33. Ray JG, Vermeulen MJ, Meier C, Cole DEC, Wyatt PR. Maternal ethnicity and risk of neural tube defects: a population-based study. Canadian Medical Association Journal. 2004;171:343-5.

34. Peake JN, Copp AJ, Shawe J. Knowledge and periconceptional use of folic acid for the prevention of neural tube defects in ethnic communities in the United Kingdom: Systematic review and meta-analysis. Birth Defects Research Part A: Clinical and Molecular Teratology. 2013;97:444-51.

35. Dept of Communities and Local Government. English Indices of deprivation 2015. In: Official Statistics, ed.2015. www.gov.uk/government/statistics/englishindices-of-deprivation-2015

36. Office for National Statistics (ONS). Live births by area of Usual Residence. 2015.

www.ons.gov.uk/peoplepopulationandcommunity/birthsdeathsandmarriages/livebirths /bulletins/birthsummarytablesenglandandwales/2015

37. Wu J, Morris JK. The population prevalence of Down's syndrome in England and Wales in 2011. European Journal of Human Genetics. 2013;21:1016-9.

38. Boulet SL, Yang Q, Mai C, et al. Trends in the postfortification prevalence of spina bifida and anencephaly in the United States. Birth Defects Research Part A:

Clinical and Molecular Teratology. 2008;82:527-32. 
Table 1 Estimated births and survivors with isolated spina bifida, spina bifida with hydrocephalus and Down syndrome in England \& Wales, $1998-2013$

\begin{tabular}{|c|c|c|c|c|c|c|c|c|c|c|}
\hline \multirow{2}{*}{$\begin{array}{c}\text { Year of } \\
\text { birth }\end{array}$} & \multirow{2}{*}{$\begin{array}{c}\text { Survival } \\
\text { age }\end{array}$} & \multicolumn{3}{|c|}{ Isolated spina bifida } & \multicolumn{3}{|c|}{ Spina bifida with hydrocephalus } & \multicolumn{3}{|c|}{ Down syndrome } \\
\hline & & $\begin{array}{c}\text { Conditional } \\
\text { Survival } \\
\text { estimate* }\end{array}$ & $\begin{array}{l}\text { Cases } \\
\text { born } \ddagger\end{array}$ & $\begin{array}{c}\text { Cases } \\
\text { surviving } \\
\text { to } 2014 \\
\end{array}$ & $\begin{array}{c}\text { Conditional } \\
\text { Survival } \\
\text { estimate* }^{*}\end{array}$ & $\begin{array}{l}\text { Cases } \\
\text { born! }\end{array}$ & $\begin{array}{c}\text { Cases } \\
\text { surviving to } \\
2014 \\
\end{array}$ & $\begin{array}{c}\text { Conditional } \\
\text { Survival } \\
\text { estimate* }^{*}\end{array}$ & $\begin{array}{l}\text { Cases } \\
\text { born† }\end{array}$ & $\begin{array}{c}\text { Cases } \\
\text { surviving to } \\
\mathbf{2 0 1 4} \\
\end{array}$ \\
\hline 1998 & 16 & 92.0 & 56 & 52 & 70.0 & 41 & 29 & 88.5 & 631 & 558 \\
\hline 1999 & 15 & 92.6 & 55 & 51 & 71.7 & 40 & 29 & 89.3 & 602 & 538 \\
\hline 2000 & 14 & 93.1 & 53 & 50 & 73.4 & 39 & 29 & 90.1 & 591 & 533 \\
\hline 2001 & 13 & 93.6 & 52 & 49 & 75.0 & 38 & 29 & 90.9 & 576 & 524 \\
\hline 2002 & 12 & 94.1 & 53 & 49 & 76.5 & 39 & 30 & 91.6 & 585 & 536 \\
\hline 2003 & 11 & 94.5 & 55 & 52 & 78.0 & 40 & 31 & 92.3 & 613 & 565 \\
\hline 2004 & 10 & 94.9 & 56 & 54 & 79.4 & 41 & 33 & 92.9 & 661 & 614 \\
\hline 2005 & 9 & 95.2 & 57 & 54 & 80.7 & 42 & 34 & 93.3 & 741 & 692 \\
\hline 2006 & 8 & 95.6 & 59 & 56 & 81.9 & 43 & 35 & 94.0 & 758 & 712 \\
\hline 2007 & 7 & 95.9 & 61 & 58 & 83.1 & 45 & 37 & 94.5 & 718 & 679 \\
\hline 2008 & 6 & 96.2 & 63 & 60 & 84.2 & 46 & 39 & 95.0 & 750 & 712 \\
\hline 2009 & 5 & 96.5 & 62 & 60 & 85.3 & 46 & 39 & 95.4 & 788 & 752 \\
\hline 2010 & 4 & 96.8 & 64 & 62 & 86.4 & 47 & 40 & 95.9 & 731 & 701 \\
\hline 2011 & 3 & 97.0 & 64 & 62 & 87.4 & 47 & 41 & 96.3 & 752 & 724 \\
\hline 2012 & 2 & 97.2 & 64 & 63 & 88.5 & 47 & 42 & 96.8 & 772 & 747 \\
\hline 2013 & 1 & 97.5 & 62 & 60 & 89.8 & 45 & 41 & 97.4 & 716 & 698 \\
\hline TOTAL & - & & 937 & 892 & & 686 & 556 & & 10,985 & 10,285 \\
\hline
\end{tabular}

*Modelled survival conditional on year of birth and survival age, modelled using cases born 1985-2003 to mothers resident in the North of England

$\dagger$ Actual cases

tEstimated cases based on average prevalence in the North of England 
Table 2 Estimated births and survivors with isolated spina bifida, spina bifida with hydrocephalus and Down syndrome in England \& Wales, $2004-2019$

\begin{tabular}{|c|c|c|c|c|c|c|c|c|c|c|}
\hline \multirow{2}{*}{$\begin{array}{c}\text { Year of } \\
\text { birth }\end{array}$} & \multirow{2}{*}{$\begin{array}{l}\text { Survival } \\
\text { age }\end{array}$} & \multicolumn{3}{|c|}{ Isolated spina bifida } & \multicolumn{3}{|c|}{ Spina bifida with hydrocephalus } & \multicolumn{3}{|c|}{ Down syndrome } \\
\hline & & $\begin{array}{c}\text { Conditional } \\
\text { Survival } \\
\text { estimate* }\end{array}$ & $\begin{array}{l}\text { Cases } \\
\text { born } \nmid\end{array}$ & $\begin{array}{c}\text { Cases } \\
\text { surviving } \\
\text { to } 2020 \\
\end{array}$ & $\begin{array}{c}\text { Conditional } \\
\text { Survival } \\
\text { estimate* }^{*}\end{array}$ & $\begin{array}{l}\text { Cases } \\
\text { born }\end{array}$ & $\begin{array}{c}\text { Cases } \\
\text { surviving to } \\
\mathbf{2 0 2 0}\end{array}$ & $\begin{array}{c}\text { Conditional } \\
\text { Survival } \\
\text { estimate* }\end{array}$ & $\begin{array}{l}\text { Cases } \\
\text { born } \ddagger\end{array}$ & $\begin{array}{c}\text { Cases } \\
\text { surviving to } \\
2020\end{array}$ \\
\hline 2004 & 16 & 94.8 & 56 & 54 & 79.1 & 41 & 32 & 92.5 & 661 & 611 \\
\hline 2005 & 15 & 95.2 & 57 & 54 & 80.4 & 42 & 33 & 93.1 & 741 & 690 \\
\hline 2006 & 14 & 95.5 & 59 & 56 & 81.7 & 43 & 34 & 93.6 & 758 & 710 \\
\hline 2007 & 13 & 95.9 & 61 & 58 & 82.8 & 45 & 36 & 94.1 & 718 & 676 \\
\hline 2008 & 12 & 96.2 & 63 & 60 & 83.9 & 46 & 37 & 94.6 & 750 & 709 \\
\hline 2009 & 11 & 96.4 & 62 & 60 & 85.0 & 46 & 39 & 95.0 & 788 & 749 \\
\hline 2010 & 10 & 96.7 & 64 & 62 & 86.0 & 47 & 39 & 95.4 & 731 & 697 \\
\hline 2011 & 9 & 96.9 & 64 & 62 & 86.9 & 47 & 41 & 95.8 & 752 & 720 \\
\hline 2012 & 8 & 97.2 & 64 & 63 & 87.8 & 47 & 41 & 96.1 & 772 & 742 \\
\hline 2013 & 7 & 97.4 & 62 & 60 & 88.6 & 45 & 42 & 96.5 & 716 & 691 \\
\hline 2014 & 6 & 97.6 & 61 & 60 & 89.4 & 45 & 40 & 96.8 & 746 & 722 \\
\hline 2015 & 5 & 97.7 & 62 & 60 & 90.1 & 47 & 41 & 97.1 & 763 & 741 \\
\hline 2016 & 4 & 97.9 & 61 & 60 & 90.9 & 47 & 41 & 97.3 & 779 & 759 \\
\hline 2017 & 3 & 98.1 & 63 & 62 & 91.6 & 47 & 41 & 98.0 & 791 & 773 \\
\hline 2018 & 2 & 98.2 & 63 & 62 & 92.3 & 47 & 42 & 98.0 & 809 & 793 \\
\hline 2019 & 1 & 98.4 & 64 & 63 & 93.2 & 47 & 43 & 98.4 & 824 & 810 \\
\hline TOTAL & - & - & 987 & 956 & - & 730 & 623 & - & 12,100 & 11,592 \\
\hline
\end{tabular}

*Modelled survival conditional on year of birth and survival age, modelled using cases born 1985-2003 to mothers resident in the North of England

$\uparrow$ Predicted cases

†ctual cases 2004-2013, predicted cases 2014-2019

Please note, surviving cases may not exactly sum to the total due to rounding error 
